\title{
Restenosis is associated with prothrombotic plasma fibrin clot characteristics in endovascularly treated patients with critical limb ischemia
}

\author{
Tomasz Nowakowski $^{1}$ (D) Krzysztof Piotr Malinowski ${ }^{2,3} \cdot$ Rafał Niżankowski $^{1} \cdot$ Teresa Iwaniec $^{4} \cdot$ Anetta Undas $^{5,6}$
}

Published online: 14 February 2019

(c) The Author(s) 2019

\begin{abstract}
Introduction Hypolysible fibrin clots composed of tightly packed fibers characterize patients with peripheral artery disease (PAD) especially those with critical limb ischemia (CLI). Little is known about the impact of a prothrombotic clot phenotype on restenosis following endovascular revascularization in CLI. The goal of this study was to compare fibrin clot properties and their determinants in CLI patients with restenosis after endovascular treatment (ET) and those free of this complication. Methods 85 patients with CLI and restenosis within 1 year after ET on optimal pharmacotherapy and 47 PAD control patients without restenosis were included into the study. Plasma fibrin clot permeability (Ks, a measure of the average pore size in the fibrin network) and clot lysis time (CLT) with its potential determinants were determined. During follow-up, the composite endpoint including re-intervention, amputation and death was assessed.

Results Compared with the control group, patients with restenosis had reduced $\mathrm{K}_{\mathrm{s}}(-9.5 \%, p<0.001)$, prolonged CLT $(+12.4 \%, p=0.003)$, higher thrombin generation $(+7.9 \%, p<0.001)$ and elevated von Willebrand factor $(\mathrm{vWF})$ antigen $(+14.2 \%, p<0.001)$. During a 24 months follow-up the composite endpoint occurred in 54 CLI patients with restenosis $(63.5 \%)$ and nine control patients $(19.1 \%, p<0.001)$ with no association with baseline $\mathrm{K}_{\mathrm{s}}$ and CLT.

Conclusion The increased thrombin formation and unfavorable fibrin clot properties occur in patients with CLI who experienced restenosis despite optimal endovascular and pharmacological therapy.
\end{abstract}

Keywords Fibrin clot $\cdot$ Peripheral arterial disease $\cdot$ Endovascular treatment $\cdot$ In-stent restenosis

\section{Highlights}

Electronic supplementary material The online version of this article (https://doi.org/10.1007/s11239-019-01826-9) contains supplementary material, which is available to authorized users.

Tomasz Nowakowski mmnowako@cyf-kr.edu.pl

Krzysztof Piotr Malinowski krzysztof.malinowski@kcri.org

Rafał Niżankowski

rtn@wp.pl

Teresa Iwaniec

teresaiwaniec@poczta.fm

Anetta Undas mmundas@cyf-kr.edu.pl
- Plasma fibrin clot permeability and clot lysis time are non-standard but clinically useful tools for atherothrombotic risk assessment.

- CLI patients with restenosis after endovascular treatment demonstrate unfavorable clot characteristics.

1 Department of Angiology, Jagiellonian University Medical College, 8 Skawinska St, 31-066 Krakow, Poland

2 Krakow Cardiovascular Research Institute, Krakow, Poland

3 Institute of Public Health, Faculty of Health Science, Jagiellonian University Medical College, Krakow, Poland

4 Department of Medicine, Jagiellonian University Medical College, Krakow, Poland

5 Institute of Cardiology, Jagiellonian University Medical College, Krakow, Poland

6 John Paul II Hospital, Krakow, Poland 
- The association of prothrombotic clot features and poor outcomes in endovascularly treated CLI patients is not evident.

- Prothrombotic clot phenotype might be modified by tailored pharmacotherapy especially anticoagulation which should be evaluated in future studies in this group of patients.

\section{Introduction}

Peripheral artery disease (PAD) is a common age-dependent disease with its prevalence up to $18-20 \%$ in patients over 70 years of age. The prevalence of intermittent claudication is $3-7 \%$ of patients and critical limb ischemia (CLI) the most advanced form of PAD, associated with a drastic limitation of quality of life, amputation, increased cardiovascular events and mortality occurs in $1-3 \%$ of patients with PAD with a likely rising prevalence in the future [1-5]. The 1 year incidence of major amputations (above the ankle), as well as MI or stroke in patients with CLI without revascularization reaches $30-50 \%$ and death occurs in up to $25 \%$ in the five following years $[1,6]$.

The most effective treatment of CLI is surgical or endovascular revascularization of the endangered limb, with similar rates of amputations, amputation-free survival and mortality [7-9]. Known factors that improve outcomes of ET in CLI involve drug eluting stents, drug eluting balloons, endovascular atherectomy, cutting balloons and retrograde tibiopedal access $[4,10,11]$. It is unclear whether any hemostatic parameters may contribute to outcomes of such therapy.

Enhanced blood coagulation linked to the systematic inflammatory state, reflected among others by elevated plasma fibrinogen, is implicated in PAD and its complications [12]. The conversion of plasma fibrinogen into fibrin and fibrin clot formation constitute the final step of the blood coagulation. Fibrinogen and fibrin promote plaque growth [13]. Numerous environmental and genetic factors influence fibrin clot characteristics and plasma fibrinogen concentrations and its function are of key importance [14]. Of note, most PAD risk factors such as diabetes, arterial hypertension, cigarette smoking, have been demonstrated as unfavorable modulators of fibrin clot properties [15].

It has been shown that dense fibrin networks composed of thin and tightly packed fibers with relatively reduced susceptibility to lysis characterize PAD [16]. Altered fibrin clot structure and function were found in relatively young individuals with intermittent claudication, in the healthy first-degree relatives of patients with claudication and in premature PAD patients [17-19]. In 2011 we reported unfavorable fibrin clot properties also in patients with advanced
PAD especially in those with worse clinical outcomes during 5 years of follow-up [20].

Until now there have been no reports assessing the impact of the prothrombotic clot phenotype on restenosis following endovascular revascularization in CLI. We hypothesized that PAD patients with CLI who experienced restenosis despite optimal endovascular and pharmacological treatment characterize more prothrombotic fibrin clot properties involving denser fiber meshwork relatively resistant to lysis compared with those with good outcomes at a 1 year follow-up.

\section{Patients and methods}

Among 697 patients with CLI defined according TASC criteria [1], treated endovascularly at the Department of Angiology of the Jagiellonian University in Cracow between February 2014 and February 2016, we screened and enrolled 140 consecutive patients in whom symptomatic restenosis in the treated segment occurred over the 12 month followup period.

Exclusion criteria were: recent ( $<6$ months) deep vein thrombosis, pulmonary embolism, acute coronary syndrome or cerebrovascular episode, known malignancy, signs of acute infection, end-stage renal failure and oral anticoagulant therapy (International Normalized Ratio [INR] > 1.5). Patients with premature cessation of antiplatelet drugs $(n=17)$, with suboptimal result of the percutaneous angioplasty (PTA) during the primary procedure $(n=12)$ and those with incomplete laboratory data $(n=5)$ were also excluded.

The control group comprised 47 PAD outpatients with similar cardiovascular risk factors treated percutaneously (initially 32 CLI patients and 15 non CLI patients), who demonstrated improvement in limb ischemia, pain relief and no symptoms of restenosis in the last 12 months after PTA.

CAD was defined as a history of MI, coronary intervention, or hospitalization for angina symptoms. Diabetes was diagnosed based on the use of insulin or oral hypoglycemic agents. Cerebrovascular disease was defined as a documented history of stroke or transient ischemic attack (TIA). Renal failure (RF) was defined as chronic kidney disease with estimated glomerular filtration rate [eGFR] below $60 \mathrm{ml} / \mathrm{min} / 1.73 \mathrm{~m}^{2}$.

Dyslipidemia was defined as a history of diagnosed and treated hypercholesterolemia or/and hypertriglyceridemia. Heart failure diagnosis was based on the hospitalization history or typical symptoms/signs and hypertension diagnosis was based on the history of antihypertensive treatment or elevated blood pressures over 140/90 mm Hg. 


\section{Endovascular procedure and angiographic evaluation}

All patients qualified for repeated endovascular treatment received dual antiplatelet therapy (aspirin $75 \mathrm{mg} / \mathrm{d}$ and clopidogrel $75 \mathrm{mg} / \mathrm{d}$ or ticagrelor $90 \mathrm{mg}$ BID). Patients with the highest thromboembolic risk qualified to endovascular treatment immediately (ischemic exacerbation, rapid progression of ulceration/necrosis) received additionally low-molecularweight heparin (LMWH) at prophylactic or half-therapeutic dose before ET with continuation for 4 weeks after the procedure.

All angiograms of primary and re-intervention were independently analyzed off-line by 2 experienced investigators (TN, MK) unaware of the fibrin clot data. All treated segments were analyzed carefully for the presence of unfavorable outcome including dissection limiting vessel flow, peripheral emboli or stent under expansion. Stenosis was defined as significant based on visual inspection or when the degree of stenosis measured with Quantitative Vascular/Coronary Angiography (QVA/QCA) software (Siemens, Germany) was $>50 \%$ of lumen diameter [21].

\section{Postprocedural follow-up}

During follow-up after the primary procedure clinical improvement or worsening of the treated limb were evaluated in all patients. Non-invasive tests were also performed. Ankle-brachial index, toe-brachial index (TBI) assessment and duplex ultrasound imaging were performed at 1, 3, 6 and 12 months after primary ET. Regardless of clinical signs and symptoms the initial diagnosis of the restenosis was made using non-invasive tests-primarily ultrasound imaging. Patients with restenosis in the previously treated vessel in ultrasound examination were qualified for angioplasty. Digital subtraction angiography (DSA) which finally confirmed the diagnosis of restenosis was done during the re-PTA procedure.

The restenosis was defined as a reoccurrence of the narrowing of the lumen of a successfully treated vessel segment with more than $50 \%$ of artery diameter reduction in DSA.

Patients and their families were instructed about pharmacological treatment after the procedure. They were also encouraged to stop smoking.

The composite endpoint included re-intervention because of restenosis, major amputation and cardiovascular death.

\section{Laboratory investigations}

Blood for the laboratory tests was taken in the postprocedural follow-up period up to 12 months after index PTA both in patients with restenosis and in the control group.
In the CLI patients time of blood sampling after the primary procedure was variable and was associated with the occurance of restenosis. The mean time of blood sampling in this group was the same as the mean time of the re-intervention (22-23 weeks after the primary PTA). In the control group blood samples were taken 3 or 6 months after PTA during the follow-up visit. Blood was drawn from an antecubital vein with minimal stasis after an overnight fast, between 7 and $10 \mathrm{AM}$. In patients receiving LMWH the blood was collected over $12 \mathrm{~h}$ after the last injection.

Blood cell count, creatinine, glucose were assayed by routine laboratory techniques. eGFR was calculated according to the Modification of Diet in Renal Diseases (MDRD) study equation. Fibrinogen was determined using the Clauss method and hs-CRP by the latex nephelometry (Siemens, Marburg, Germany). Commercially available immunoenzymatic assays were used to determine tissue-type plasminogen activator antigen (t-PA:Ag), plasminogen activator inhibitor-1 antigen (PAI-1:Ag) (both American Diagnostica, Stamford, CT, USA) and thrombin activatable fibrinolysis inhibitor antigen (TAFIa/ia) (Imubind TAFIa/ai antigen ELISA; American Diagnostica). Von Willebrand factor (vWF) antigen was measured with immunoturbidimetry using the STA Liatest kit (Diagnostica Stago, Asniéres, France). Plasminogen and $\alpha_{2}$-antiplasmin were measured by chromogenic assays (STA Stachrom antiplasmin and STA Stachrom plasminogen, Diagnostica Stago, Asniéres, France).

Thrombin generation was assessed using the Calibrated Automated Thrombogram (Thrombinoscope BV, Maastricht, the Netherlands) according to the manufacturer's instructions in the 96-well plate fluorometer (Ascent Reader, Thermolabsystems OY, Helsinki, Finland) [22]. The area under the curve (AUC), as a measure of the endogenous thrombin potential (ETP), expressed the dynamic of thrombin generation in the plasma sample after addition of TF. Each plasma sample was analyzed in duplicate. All intra-assay and interassay coefficients of variation were below $7 \%$.

\section{Plasma fibrin clot analysis}

In citrated plasma (vol/vol 9:1 of $3.2 \%$ sodium citrate), the following variables describing plasma clot structure and lysability were determined in duplicate by technicians blinded to the origin of the samples (intra-assay and inter-assay coefficients of variation, $5-7 \%$ ).

\section{Clot permeability}

Permeation properties of fibrin clots were investigated as previously described [23]. At a glance, after incubation 
of $20 \mathrm{mmol} / \mathrm{L}$ calcium chloride, $1 \mathrm{U} / \mathrm{mL}$ human thrombin (Sigma, St. Louis, MO) and the citrated plasma, tubes containing the clots were connected to a reservoir of a buffer (0.01 MTris, $0.1 \mathrm{M} \mathrm{NaCl}, \mathrm{pH} 7.5)$ and its volume flowing through the gels was measured within $60 \mathrm{~min}$. A permeation coefficient $\left(\mathrm{K}_{\mathrm{s}}\right)$, indicating the pore size, was calculated from the equation: $\mathrm{K}_{\mathrm{s}}=\mathrm{Q} \times \mathrm{L} \times \eta / \mathrm{t} \times \mathrm{A} \times \Delta \mathrm{p}$, where $\mathrm{Q}$ is the flow rate in time $t, L$ is the length of a fibrin gel, $\eta$ is the viscosity of liquid (in poise), $\mathrm{A}$ is the cross-sectional area (in $\mathrm{cm}^{2}$ ), and $\Delta \mathrm{p}$ is a differential pressure (in dyne/ $\mathrm{cm}^{2}$ ).

\section{Clot lysis time}

Clot lysis time (CLT) was determined as described [24, 25]. Briefly, the mixture of 10000-diluted human tissue factor (Innovin, Siemens, Marburg, Germany), $12 \mu \mathrm{mol} / \mathrm{l}$ phospholipid vesicles and $60 \mathrm{ng} / \mathrm{ml}$ recombinant t-PA (Boehringer Ingelheim, Ingelheim, Germany) was transferred to a microtitre plate and its turbidity was measured at $405 \mathrm{~nm}$ at $37^{\circ} \mathrm{C}$. CLT was defined as the time from the midpoint of the clearto-maximum-turbid transition, which represents clot formation, to the midpoint of the maximum-turbid-to-clear transition representing the clot degradation.

\section{Statistical analysis}

The study was powered to have a $90 \%$ chance of detecting a $10 \%$ difference in CLT using a p-value of 0.05 , based on the values of CLT. In order to demonstrate such a difference or greater, 32 patients were required in each group. In turn, to demonstrate such a difference in $\mathrm{K}_{\mathrm{s}}$ using a p-value of 0.05 , at least 31 patients were required in each group.

Continuous variables are expressed as mean \pm SD or otherwise stated (as median with IQR). Continuous variables were checked for normality using the Shapiro-Wilk test and compared by Student's t-test (with correction for unequal variances if appropriate) when normally distributed or by the Mann-Whitney or Wilcoxon tests for non-normally distributed variables. The Pearson or Spearman rank correlation coefficients were calculated to test the association between two variables with a normal or non-normal distribution, respectively. Odds for the 1st quartile of $K_{s}$ compared to the 4th and for the 4th quartile of CLT compared to the 1st quartile were calculated using simple logistic regression. Multiple logistic regression models were constructed stepwise backward from variables with a $p$-value $<0.2$ from simple regression models. Bayesian Information Criterion (BIC) was used as a target.

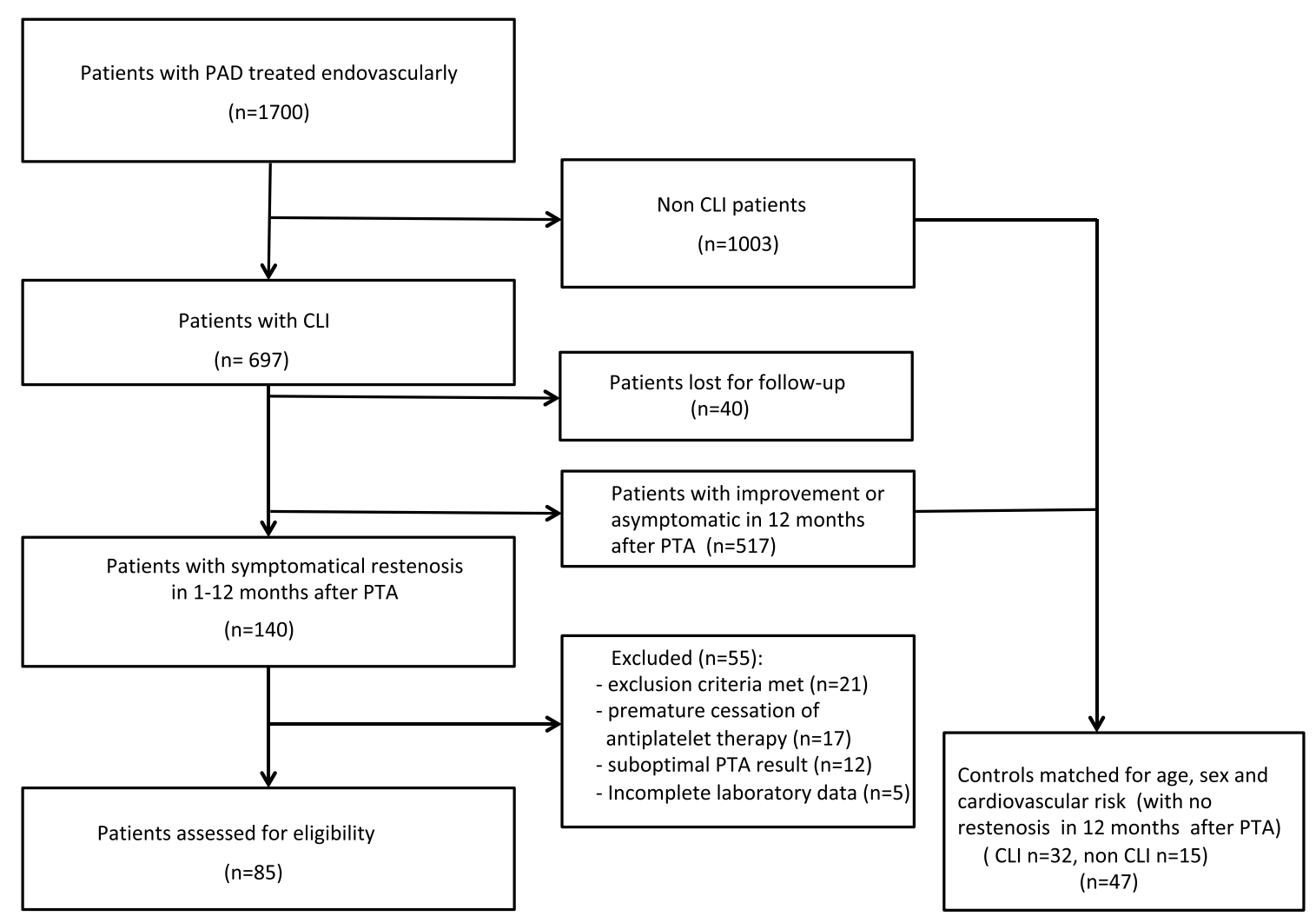

Fig. 1 Study patients recruitment and selection diagram 
Table 1 Characteristics of CLI patients with restenosis and control subjects

\begin{tabular}{|c|c|c|c|}
\hline & Restenosis group $(n=85)$ & Controls $(n=47)$ & $p$ value \\
\hline Age, years & $69.65 \pm 10.36$ & $66.89 \pm 8.46$ & 0.14 \\
\hline Male gender, n (\%) & $49(57.65)$ & $33(70.21)$ & 0.15 \\
\hline BMI, $\mathrm{kg} / \mathrm{m}^{2}$ & $25.49 \pm 4.91$ & $26.26 \pm 3.91$ & 0.13 \\
\hline Current smoking, n (\%) & $55(64.71)$ & 35 (74.47) & 0.25 \\
\hline Dyslipidemia, n (\%) & $53(62.35)$ & $26(55.32)$ & 0.43 \\
\hline Diabetes, n (\%) & $38(44.71)$ & $23(48.94)$ & 0.64 \\
\hline Hypertension, n (\%) & $73(85.88)$ & $42(89.36)$ & 0.57 \\
\hline Heart failure, n (\%) & $18(21.18)$ & $5(10.64)$ & 0.13 \\
\hline CAD, n (\%) & $35(41.18)$ & $17(36.17)$ & 0.57 \\
\hline MI & $20(23.53)$ & $9(19.15)$ & 0.56 \\
\hline PCI & $13(15.29)$ & $7(14.89)$ & 0.04 \\
\hline CABG & $5(5.88)$ & $1(2.13)$ & 0.42 \\
\hline CVD, n (\%) & $15(17.65)$ & $2(4.26)$ & 0.027 \\
\hline $\mathrm{RF}, \mathrm{n}(\%)$ & $25(29.41)$ & $5(10.64)$ & 0.013 \\
\hline \multicolumn{4}{|l|}{ PAD characteristic } \\
\hline \multicolumn{4}{|l|}{ Rutherford class } \\
\hline $3, \mathrm{n}(\%)$ & $0(0.00)$ & $15(31.91)$ & $<0.001$ \\
\hline $4, \mathrm{n}(\%)$ & $39(45.88)$ & $8(17.02)$ & \\
\hline $5, \mathrm{n}(\%)$ & $40(47.06)$ & $18(38.30)$ & \\
\hline $6, \mathrm{n}(\%)$ & $6(7.06)$ & $6(12.77)$ & \\
\hline $\mathrm{ABI}$ & $0.28 \pm 0.46$ & $0.64 \pm 0.36$ & \\
\hline TBI & $0.05 \pm 0.10$ & $0.21 \pm 0.19$ & \\
\hline \multicolumn{4}{|l|}{ Treated segment } \\
\hline Ilio-femoral, n (\%) & $9(10.59)$ & $10(21.28)$ & \\
\hline Femoro-popliteal, n (\%) & $44(51.76)$ & $17(36.17)$ & 0.12 \\
\hline $\begin{array}{l}\text { Femoro-popliteal and/or infrap- } \\
\text { opliteal, n (\%) }\end{array}$ & $32(37.65)$ & $20(42.55)$ & \\
\hline Time to restenosis (weeks) & $20.75 \pm 13.59$ & - & - \\
\hline Time to re-intervention, (w) & $23.21 \pm 14.17$ & - & - \\
\hline \multicolumn{4}{|l|}{ Medications, n (\%) } \\
\hline Statins & $85(100)$ & $47(100)$ & 1.0 \\
\hline Aspirin & $85(100)$ & $47(100)$ & 1.0 \\
\hline ACEI/ARB & $59(69.41)$ & $32(68.09)$ & 0.87 \\
\hline $\mathrm{BB}$ & $44(52.38)$ & $22(46.81)$ & 0.54 \\
\hline Calcium antagonists & $26(30.59)$ & $16(34.04)$ & 0.68 \\
\hline LMWH & $47(55.29)$ & $0(0.00)$ & $<0.001$ \\
\hline $\mathrm{P} 2 \mathrm{Y}_{12}$ & $84(98.82)$ & $13(27.66)$ & $<0.001$ \\
\hline PPI & $73(85.88)$ & $19(40.43)$ & $<0.001$ \\
\hline
\end{tabular}

Values are given as mean $\pm \mathrm{SD}$ or number (percentage)

$B M I$ body mass index; $C A D$ coronary artery disease; $M I$ myocardial infarction; $P C I$ percutaneous coronary intervention; $C A B G$ coronary by-pass graft; $C V D$ cerebrovascular disease; TIA transient ischemic attack; $R F$ renal failure; $A B I$ ankle/brachial index; $T B I$ toe/brachial index; $A S A$ acetylsalicylic acid; $A C E I$ angiotensin-converting enzyme inhibitor; $A R B$ angiotensin receptor blocker; $B B$ beta-receptor blocker; $L M W H$ low molecular weight heparin; $P 2 Y_{12} \mathrm{P}_{2} \mathrm{Y}_{12}$ receptor inhibitor; $P P I$ proton pump inhibitor 
A $p$-value $<0.05$ was considered statistically significant. All calculations were done with JMP, version 13.1 (SAS Institute Inc., Cary, NC, USA).

\section{Results}

\section{Patient characteristics}

A total of 85 patients with in-stent restenosis/re-occlusion after PTA entered the final analysis (Fig. 1).

Characteristics of patients with restenosis and control subjects were presented in Table 1 .

84 patients with restenosis $(98.7 \%)$ had at least one stent implanted during the primary procedure and one patient (1.7\%) had balloon angioplasty. During re-intervention 72 $(84.7 \%)$ patients were treated with stent implantation and 13 (15.3\%) with balloon angioplasty alone.

The mean time of restenosis occurrence was 21 weeks (3-50 weeks) and the re-intervention time in most patients $(62.4 \%)$ was $2-3$ weeks longer $(p=0.19) .32$ patients $(37.6 \%)$ required immediate intervention.

Both ABI and TBI were lower in the restenosis group. There was no significant difference with regard to the treated vascular segment of the affected limb.

Both groups did not differ in baseline routine laboratory investigations except for lower hemoglobin and eGFR in the restenosis group (Table 2).

After adjustment for severity of PAD (both groups with CLI before primary PTA), the clinical differences observed initially between the whole control group and restenosis group, as well as laboratory parameters differentiating both groups remained still significant (Table 4S, Table 5S).

\section{Hemostatic variables}

Higher thrombin generation $(+7.9 \%)$ was observed in patients with restenosis (Table 2). ETP values in this group positively correlated with fibrinogen and CRP $(r=0.51$, $p=0.0005$ and $r=0.3, p=0.003$ respectively). Moreover, $14.2 \%$ higher vWF antigen levels were found in the restenosis group (Table 2). Among fibrinolysis proteins, active TAFI levels were $5 \%$ lower also in the restenosis group $(p=0.03)$.

Patients with CLI and restenosis had reduced clot permeability $(-9.5 \%)$ and prolonged CLT $(+12.4 \%)$ compared with the control group (Fig. 2). $\mathrm{K}_{\mathrm{s}}$ and CLT showed strong associations with fibrinogen $(r=-0.55, p<0.0001$ and $r=0.56, p<0.001$, respectively). CRP correlated with $\mathrm{K}_{\mathrm{s}}$ $(\mathrm{r}=-0.36, p=0.0016)$ and CLT $(r=0.32, p=0.047)$. The univariate logistic analysis for $\mathrm{K}_{\mathrm{s}}$ and CLT in the restenosis group is shown in Table 3.

CLT inversely correlated with ABI $(r=-0.21)$ and TBI $(r=-0.21)$ in all 132 patients $(p<0.05)$.

In the control group correlations between fibrinogen concentrations and $K_{\mathrm{s}}(r=-0.55, p<0.001)$ as well as CLT $(r=0.34, p=0.03)$ were also observed.
Table 2 Laboratory parameters and fibrin clot properties measured in patients with restenosis and controls

\begin{tabular}{|c|c|c|c|}
\hline & Restenosis group $(n=85)$ & Controls $(n=47)$ & $p$ value \\
\hline Creatinine, umol/1 & $87.58 \pm 48.98$ & $76.27 \pm 23.6$ & 0.076 \\
\hline $\mathrm{eGFR}, \mathrm{ml} / \mathrm{min} / 1.73 \mathrm{~m}^{2}$ & $81.46 \pm 33.96$ & $94.17 \pm 26.9$ & 0.024 \\
\hline Hemoglobin, g/l & $12.78 \pm 1.71$ & $13.85 \pm 1.17$ & $<0.001$ \\
\hline Platelets, $\times 10^{3} / \mathrm{ul}$ & $231.35 \pm 80.84$ & $215.96 \pm 43.62$ & 0.16 \\
\hline Fibrinogen, $g / 1$ & $3.84 \pm 1.17$ & $3.69 \pm 0.63$ & 0.87 \\
\hline CRP, mg/l & $5.0(1.74 ; 15.40)$ & $5.0(5.0 ; 8.2)$ & 0.43 \\
\hline PAI-1, ng/ml & $31.1(25.45 ; 38.5)$ & $31.8(28.9 ; 34.9)$ & 0.62 \\
\hline ETP (nM.min) & $1568(1445 ; 1691.5)$ & $1441(1362 ; 1568)$ & $<0.001$ \\
\hline vWF \% & $207(167.5 ; 239.5)$ & $180(145 ; 204)$ & $<0.001$ \\
\hline TAFI ia/a \% & $96(85 ; 107)$ & $100(94 ; 108)$ & 0.03 \\
\hline Plasminogen (\%) & $105(90.5 ; 121.5)$ & $105(97 ; 119)$ & 0.98 \\
\hline$\alpha_{2}$-antiplasmin (\%) & $112.51 \pm 17.01$ & $109.77 \pm 17.76$ & 0.22 \\
\hline $\mathrm{tPA} \mathrm{Ag}, \mathrm{ng} / \mathrm{ml}$ & $10.81 \pm 2.83$ & $10.16 \pm 1.98$ & 0.12 \\
\hline$K_{\mathrm{s}}, 10^{-9} \mathrm{~cm}^{2}$ & $6.38 \pm 0.85$ & $6.98 \pm 0.79$ & $<0.001$ \\
\hline CLT, min & $107.24 \pm 22.93$ & $95.40 \pm 15.46$ & 0.003 \\
\hline
\end{tabular}

Values are given as mean $\pm \mathrm{SD}$ or median (IQR)

$e G F R$ estimated glomerular filtration rate; $C R P$ C-reactive protein; $P A I-1$ plasminogen activator inhibitor-1; ETP endogenous thrombin potential; $v W F$ von Willebrand factor; TAFI thrombin activatable fibrinolysis inhibitor; $t P A$ tissue-type plasminogen activator; $K_{s}$ permeability coefficient; $C L T$ clot lysis time 
Table 3 Univariate logistic analysis. Odds for lower quartile compared to higher quartile of $K_{\mathrm{s}}$ and odds for upper quartile compared to lower quartile of CLT in the restenosis group

\begin{tabular}{|c|c|c|c|c|}
\hline & $K_{\mathrm{s}}$ & & $C L T$ & \\
\hline Variable & $O R(95 \% \mathrm{CI})$ & $p$ value & $O R(95 \% \mathrm{CI})$ & $p$ value \\
\hline Age & $\begin{array}{l}1.00(0.94 ; \\
1.07)\end{array}$ & 0.89 & $\begin{array}{c}1.03(0.97 ; \\
1.11)\end{array}$ & 0.31 \\
\hline BMI & $\begin{array}{l}0.95(0.82 \\
1.07)\end{array}$ & 0.40 & $\begin{array}{l}0.88(0.75 \\
1.02)\end{array}$ & 0.11 \\
\hline eGFR & $\begin{array}{l}1.01(0.99 \\
1.03)\end{array}$ & 0.46 & $\begin{array}{c}0.99(0.97 ; \\
1.01)\end{array}$ & 0.31 \\
\hline Hematocrit & $\begin{array}{l}0.97(0.84 \\
1.11)\end{array}$ & 0.62 & $\begin{array}{l}0.97(0.84 ; \\
1.10)\end{array}$ & 0.60 \\
\hline PLT & $\begin{array}{l}1.00(0.99 ; \\
1.01)\end{array}$ & 0.86 & $\begin{array}{l}1.00(1.00 ; \\
1.01)\end{array}$ & 0.48 \\
\hline Fibrinogen & $\begin{array}{c}8.90(2.90 \\
49.01)\end{array}$ & 0.002 & $\begin{array}{l}2.66(1.43 ; \\
6.04)\end{array}$ & 0.007 \\
\hline CRP & $\begin{array}{l}1.12(1.04 ; \\
1.23)\end{array}$ & 0.009 & $\begin{array}{l}1.05(1.00 \\
1.13)\end{array}$ & 0.11 \\
\hline $\mathrm{ABI}$ & $\begin{array}{l}0.99(0.19 \\
3.95)\end{array}$ & 0.98 & $\begin{array}{c}0.37(0.04 \\
1.82)\end{array}$ & 0.31 \\
\hline TBI & $1.09(0.99 ; 1.2)$ & 0.09 & $\begin{array}{l}0.99(0.89 \\
1.11)\end{array}$ & 0.95 \\
\hline$K_{\mathrm{s}}$ & - & - & $\begin{array}{c}0.06(0.01 \\
0.24)\end{array}$ & 0.001 \\
\hline CLT & $\begin{array}{l}1.10(1.05 ; \\
1.18)\end{array}$ & 0.001 & - & - \\
\hline PAI-1 & $\begin{array}{c}1.17(1.07 ; \\
1.31)\end{array}$ & 0.002 & $\begin{array}{c}1.39(1.19 \\
1.76)\end{array}$ & 0.0005 \\
\hline ETP & $\begin{array}{l}1.02(1.01 ; \\
1.03)\end{array}$ & 0.004 & $\begin{array}{l}1.01(1.01 ; \\
1.02)\end{array}$ & 0.0008 \\
\hline vWF \% & $\begin{array}{c}1.01(0.99 \\
1.02)\end{array}$ & 0.39 & $\begin{array}{l}1.01(1.00 ; \\
1.03)\end{array}$ & 0.19 \\
\hline TAFI & $\begin{array}{c}1.05(1.01 ; \\
1.11)\end{array}$ & 0.044 & $\begin{array}{c}1.06(1.02 ; \\
1.13)\end{array}$ & 0.02 \\
\hline Plasminogen & $\begin{array}{c}0.95(0.90 ; \\
0.99)\end{array}$ & 0.02 & $\begin{array}{c}0.97(0.93 ; \\
1.01)\end{array}$ & 0.11 \\
\hline$\alpha_{2}$-antiplasmin & $\begin{array}{c}0.99(0.94 \\
1.03)\end{array}$ & 0.48 & $\begin{array}{c}0.98(0.95 \\
1.02)\end{array}$ & 0.37 \\
\hline $\mathrm{tPA}$ & $\begin{array}{c}1.03(0.83 \\
1.28)\end{array}$ & 0.77 & $\begin{array}{c}0.96(0.77 ; \\
1.19)\end{array}$ & 0.69 \\
\hline $\mathrm{AH}$ & $\begin{array}{c}0.14(0.02 ; \\
0.75)\end{array}$ & 0.02 & $\begin{array}{l}0.71(0.12 ; \\
3.67)\end{array}$ & 0.71 \\
\hline CAD & $0.9(0.24 ; 3.26)$ & 0.87 & $\begin{array}{c}1.47(0.44 \\
5.06)\end{array}$ & 0.67 \\
\hline MI & $\begin{array}{c}1.75(0.36 \\
8.69)\end{array}$ & 0.48 & $\begin{array}{l}1.54(0.42 ; \\
5.81)\end{array}$ & 0.51 \\
\hline $\mathrm{AF}$ & $\begin{array}{l}0.49(0.02 \\
4.24)\end{array}$ & 0.53 & $\begin{array}{c}4.71(0.62 ; \\
96.81)\end{array}$ & 0.14 \\
\hline $\mathrm{CHF}$ & $\begin{array}{c}6.9(1.33 ; \\
53.03)\end{array}$ & 0.02 & $\begin{array}{c}4.5(1.09 \\
23.57)\end{array}$ & 0.03 \\
\hline $\mathrm{DM}$ & $\begin{array}{c}0.26(0.06 \\
0.98)\end{array}$ & 0.047 & $\begin{array}{c}1.21(0.36 \\
4.16)\end{array}$ & 0.75 \\
\hline CVD & $\begin{array}{c}0.89(0.75 \\
1.33)\end{array}$ & 0.07 & $1.0(0.24 ; 4.25)$ & 1.0 \\
\hline Smoking & $\begin{array}{c}1.69(0.43 ; \\
7.45)\end{array}$ & 0.45 & $\begin{array}{c}0.63(0.15 ; \\
2.40)\end{array}$ & 0.49 \\
\hline
\end{tabular}

Table 3 (continued)

\begin{tabular}{lcccc}
\hline & $K_{\mathrm{s}}$ & \multicolumn{3}{c}{$C L T$} \\
\hline RF & $0.30(0.04 ;$ & 0.14 & $0.78(0.19 ;$ & 0.72 \\
& $1.46)$ & & $3.13)$ & \\
Statin & $0.08(0.001 ;$ & 0.02 & $0.32(0.002 ;$ & 0.36 \\
& $0.86)$ & & $6.31)$ & \\
LMWH & $0.67(0.18 ;$ & 0.52 & $\begin{array}{l}3.33 \\
(0.95,12.71)\end{array}$ & 0.05 \\
& $2.37)$ & & $3.08(0.96 ;$ & 0.06 \\
P2Y $_{12}$ & $4.76(1.31 ;$ & 0.02 & $11.08)$ & \\
& $22.9)$ & & & \\
& & &
\end{tabular}

${ }^{\mathrm{a}}$ In comparison to patients without mentioned co-morbidities and medical therapy

Abbreviations: see Tables 1 and 2

\section{Follow-up}

During a mean follow-up of 24.3 months (range, 12-36 months), 54 patients (63.5\%) with CLI and restenosis reached a composite endpoint including re-intervention, amputation and death. 18 patients $(21.2 \%)$ have died-mostly of cardiovascular events (heart failure, acute coronary syndrome). 38 patients $(44.7 \%)$ had at least one re-intervention but only five patients lost the limb (5.8\%). In the control group one patient died (2.1\%), 8 underwent recurrent PTA because of restenosis (17\%) and none had an amputation.

Patients with restenosis and worse outcomes had more frequent RF, smoking history, concomitant CAD and CVD. No differences in fibrin clot properties and other laboratory variables in this group were observed.

\section{Discussion}

This study demonstrates that altered plasma clot properties and impaired susceptibility to lysis are associated with the history of restenosis within the first year of endovascular treatment in PAD patients with CLI. In patients with CLI and restenosis plasma fibrin clots are less permeable and more resistant to lysis compared to those PAD patients who did not experience restenosis after ET. These findings extended our knowledge on the role of prothrombotic clot features and hypolysibility in advanced PAD.

Our results are consistent with previous investigations in patients with PAD without CLI $[17,18,20]$. While fibrin clots presented more prothrombotic features in CLI patients with restenosis, both groups did not differ according to main inflammatory determinants of clot characteristics, namely fibrinogen and CRP. However, increased levels of fibrinogen and CRP correlated with lower clot permeability and prolonged lysis, which is consistent with data from previous studies $[14,26]$. 

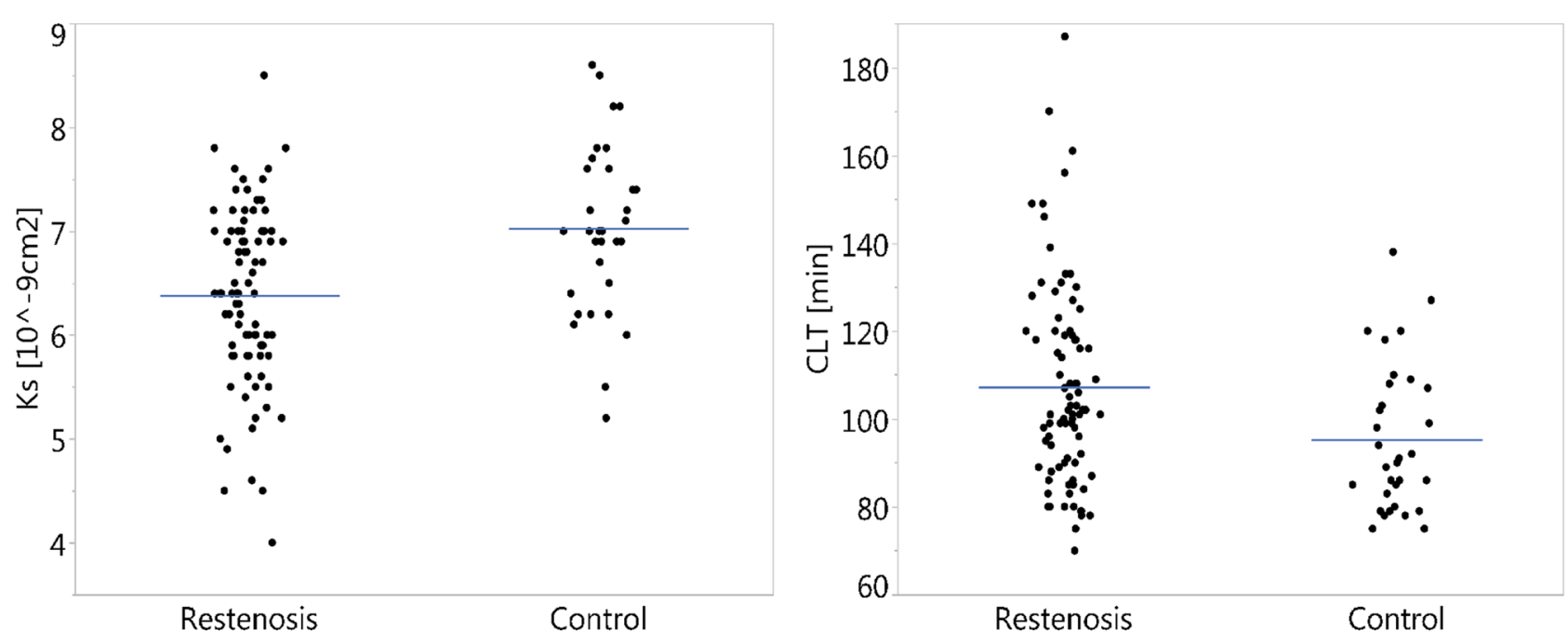

Fig. 2 Scatter plots of the permeability coefficient $\left(K_{\mathrm{s}}\right)$ and clot lysis time (CLT) measurements in patients with restenosis and control group. Lines represent mean values for both parameters, $\mathrm{p}<0.005$

In our data interpretation, several confounding factors should be addressed. We demonstrated that the involvement of unfavorable fibrin clot properties in patients with CLI and restenosis is similar to that reported previously in individuals with re-occlusion (stent thrombosis) following stent implantation in the coronary arteries [25, 27]. However the mechanism of in-stent restenosis remains different than in-stent thrombosis. Most of the known causes of restenosis produce acute or late stent thrombosis where incomplete endothelialization and persistent fibrin-rich thrombi play a crucial role [28]. It is difficult to determine what is the contribution of thrombosis and inflammatory-related neointimal proliferation in restenosis among patients with PAD.

We also observed increased vWF especially in patients of the restenosis group. This marker was found as the independent predictor of fibrin-rich intracoronary thrombus presence in patients with acute MI [29]. Moreover, the extent of $\mathrm{vWF}$ release in patients with acute coronary syndrome was an independent predictor of adverse clinical outcome [30]. Although previous observations of the association of $\mathrm{vWF}$ and restenosis in PAD are not consistent [31, 32], in the current study elevated levels of vWF in PAD patients could indicate on endothelial cell dysfunction and its contribution to restenosis process in PAD.

Thrombin generation was higher in CLI patients with restenosis and strongly correlated with fibrin clot parameters. Moreover, ETP constituted one of the independent predictors for low $K_{\mathrm{s}}$ values and high CLT values. This finding is consistent with observations that higher thrombin concentrations produce less permeable clots, composed of a dense fiber network resistant to lysis [33]. Elevated ETP could be involved in atherosclerosis and progression of PAD in part through fibrin-mediated mechanisms. Although in many studies in patients with CAD and fewer in patients with PAD thrombin generation (in vivo) and ETP (ex vivo) were altered, it is not clear how important is the relationship between high thrombin generation and atherosclerosis [34].

Patients were receiving antiplatelet drugs, and it is known that aspirin positively affects clot structure [35]. In our study altered plasma clot properties with more pronounced negative characteristics in the restenosis group were apparent despite aspirin and clopidogrel administration. The beneficial effect of the statins on fibrin properties has also been described [36]. However, all patients in this study were taking statins and the impact of these medications could not have been assessed.

The choice of a $10 \%$ difference in CLT or clot permeability as biologically important deserves a comment. We chose this difference based on our praevious studies using a similar methodology $[37,38]$. Because of synergistic actions of multiple prothrombotic alterations 10-20\% differences could be sufficient to modulate the hypercoagualable state. In our recent cohort study we reported that similar differences in fibrin clot properties have a prognostic value in terms of the risk of recurrent thromboembolism during follow-up [38].

Further studies are needed to validate clinical relevance of our findings among patients with CLI.

\section{Limitations}

This study has several limitations. First, the number of patients was limited, though the study was adequately powered however, the subgroup analysis especially with long outcomes should be interpreted with caution. Secondly, we did not analyze a potential impact of blood cells and platelets on fibrin clot structure/function. Third, other fibrin 
clot modifiers including oxidative stress and homocysteine have not been investigated in the current study either [18]. Although fibrin parameters can be changed by medical treatment, we did not expect any differences of the impact of such management on these parameters since all patients and controls were treated similarly. The important difference with antiplatelet and anticoagulation treatment was associated with the re-PTA procedure. Before endovascular procedure almost all CLI patients were taken $\mathrm{P} 2 \mathrm{Y}_{12}$ inhibitors and half of them received LMWH (Table 1). We did not measure anti-FXa activity before blood sampling to confirm that the patients receiving LMWH had no residual anticoagulant effects. However, $>12 \mathrm{~h}$ after the last injection, such effects are rather unlikely.

Finally, an important limitation is the way of recruitment. All the patients were recruited after the primary endovascular procedure with a 12 months follow-up period. To achieve an adequate number of patients in the control group, we enrolled some patients with severe claudication (32\%), what influenced on differences in PAD characteristic between analyzed groups and could have an influence on some clinical outcomes. However after adjustment for the severity of PAD (both restenosis and control group with CLI), the clinical and laboratory differences observed initially between the whole control group and restenosis group remained significant.

Our findings cannot be easily extrapolated to patients with severe comorbidities, who were excluded from our study, particularly those with end-stage renal failure shown to alter plasma fibrin properties unfavorably $[15,16]$.

\section{Conclusions}

Our study demonstrates that fibrin clots in patients with CLI who experienced restenosis despite optimal endovascular and pharmacological therapy are more prothrombotic involving denser fiber meshwork relatively resistant to lysis compared with those with good outcomes over a 1 year follow-up. However, because of the complexity of interactions between cardiovascular risk factors, coagulation proteins, platelets function and pharmacotherapy, our observation does not allow to determine which CLI patients with impaired fibrin clot properties would develop poor outcomes. Further studies are required to confirm hypothetical benefits of prolonged anticoagulant therapy in this subgroup of patients.

Acknowledgements We thank Dr. Łukasz Partyka for providing language help and valuable comments.

Author contributions $\mathrm{AU}$ and $\mathrm{TN}$ conceived and designed the research project. TN and TI collected the data. KM and TN analyzed the data.
AU approved the final version of the manuscript. TN, KM and RN edited and revised the manuscript.

Funding This research received no specific grant from any funding agency in the public, commercial, or not-for-profit sectors.

\section{Compliance with ethical standards}

Conflict of interest All authors declare that they have no potential conflicts of interest

Ethical approval The study was approved by the Jagiellonian University Ethics Committee, and patients provided written informed consent. The study was conducted according to the ICH-GCP guidelines and relevant local and international regulations including but not limited to the 1964 Declaration of Helsinki (WMA).

Open Access This article is distributed under the terms of the Creative Commons Attribution 4.0 International License (http://creativeco mmons.org/licenses/by/4.0/), which permits unrestricted use, distribution, and reproduction in any medium, provided you give appropriate credit to the original author(s) and the source, provide a link to the Creative Commons license, and indicate if changes were made.

\section{References}

1. Norgren L, Hiatt WR, Dormandy JA, Nehler MR, Harris KA, Fowkes FG (2007) TASC II Working Group. Inter-society consensus for the management of peripheral arterial disease. Eur J Vasc Endovasc Surg 33(Suppl 1):S1-S75

2. Wierzchowski P, Dereziński T, Migdalski A, Woda Ł, Wąsikowska B, Jakubowski G et al (2017) Cross-sectional study of the ankle- brachial index and cardiovascular risk factors in postmenopausal women. Kardiol Pol 75:486-494. https://doi. org/10.5603/KP.a2017.0016

3. Fowkes F, Rudan D, Rudan I, Aboyans V, Denenberg JO, McDermott MM et al (2013) Comparison of global estimates of prevalence and risk factors for peripheral artery disease in 2000 and 2010: a systematic review and analysis. Lancet 382:1329-1340

4. Shishehbor MH, White CJ, Gray BH, Menard MT, Lookstein R, Rosenfield K et al (2016) Critical limb ischemia. An expert statement. J Am Coll Cardiol 68:2002-2015

5. Varu VN, Hogg ME, Kibbe MR (2010) Critical limb ischemia. J Vasc Surg 51:230-241

6. Kinlay S (2016) Management of critical limb ischemia. Circ Cardiovasc Interv 9:e001946

7. Aboyans V, Ricco JB, Bartelink ML, Björck M, Brodmann M, Cohnert $\mathrm{T}$ et al (2017) ESC guidelines on the diagnosis and treatment of peripheral artery diseases, in collaboration with the European society for vascular surgery. Document covering atherosclerotic disease of extracranial carotid and vertebral, mesenteric, renal, upper and lower extremity arteries. The task force on the diagnosis and treatment of peripheral artery diseases of the European society of cardiology (ESC) and of the European society for vascular surgery (ESVS). Eur Heart J 00:1-60. https://doi. org/10.1093/eurheartj/ehx095

8. Jones WS, Dolor RJ, Hasselblad V, Vemulapalli S, Subherwal S, Schmit K et al (2014) Comparative effectiveness of endovascular and surgical revascularization for patients with peripheral artery disease and critical limb ischemia: systematic review 
of revascularization in critical limb ischemia. Am Heart $\mathbf{J}$ 167:489-498

9. Bisdas T, Borowski M, Stavroulakis K, Torsello G, for the CRITISCH Collaborators (2016) Endovascular therapy versus bypass surgery as first-line treatment strategies for critical limb ischemia results of the interim analysis of the CRITISCH registry. J Am Coll Cardiol 24:2557-2565. https://doi.org/10.1016/j. jcin.2016.09.039

10. Fusaro M, Cassese S, Ndrepepa G, Tepe G, King L, Ott I et al (2013) Drug-eluting stents for revascularization of infrapopliteal arteries: an updated meta-analysis of randomized trials. J Am Coll Cardiol 12:1284-1293

11. Montero-Baker M, Schmidt A, Bräunlich S, Ulrich M, Thieme M, Biamino G et al (2008) Retrograde approach for complex popliteal and tibioperoneal occlusions. J Endovasc Ther 15:594-604

12. Tzoulaki I, Murray GD, Price JF, Smith FB, Lee AJ, Rumley A et al (2006) Hemostatic factors, inflammatory markers and progressive peripheral atherosclerosis: the Edinburgh Artery Study. Am J Epidemiol 63:334-341

13. Smith EB (1994) Lipids and plasma fibrinogen: early and late composition of the atherosclerotic plaque. Cardiologia 39(12 Suppl 1):169-172

14. Scott EM, Ariëns RA, Grant PJ (2004) Genetic and environmental determinants of fibrin structure and function. Relevance to clinical disease. Arterioscler Thromb Vasc Biol 24:1558-1566

15. Undas A, Ariëns RA (2011) Fibrin clot structure and function a role in the pathophysiology of arterial and venous thromboembolic diseases. Arterioscler Thromb Vasc Biol 31:88-99

16. Undas A (2014) Fibrin clot properties and their modulation in thrombotic disorders. Thromb Haemost 112:32-42

17. Bhasin N, Parry DJ, Scott DJ, Ariëns RA, Grant PJ, West RM (2009) Regarding Altered fibrin clot structure and function in individuals with intermittent claudication. J Vasc Surg 49:1088-1089

18. Bhasin N, Ariëns RA, West RM, Parry DJ, Grant PJ, Scott DJ (2008) Altered fibrin clot architecture and function in the healthy first-degree relatives of subjects with intermittent claudication. J Vasc Surg 48:1497-1503

19. Okraska-Bylica A, Wilkosz T, Słowik L, Bazanek M, Konieczyńska M, Undas A (2012) Altered fibrin clot properties in patients with premature peripheral artery disease. Pol Arch Med Wewn 122:608-615

20. Undas A, Nowakowski T, Ciesla-Dul M, Sadowski J (2011) Abnormal plasma fibrin clot characteristics are associated with worse clinical outcome in patients with peripheral arterial disease and thromboangiitis obliterans. Atherosclerosis 215:481-486

21. Beregi J, Martin-Teule C, Trogrlic S, Meunier J, Crochet D (1999) Quantitative angiography: state of the art for peripheral vascular applications. J Radiol 80:835-841

22. Hemker HC, Giesen P, Al Dieri R, Regnault V, de Smedt E, Wagenvoord R et al (2003) Calibrated automated thrombin generation measurement in clotting plasma. Pathophysiol Haemost Thromb 33:4-15

23. Undas A, Zawilska K, Ciesla-Dul M, Lehmann-Kopydłowska A, Skubiszak A, Ciepłuch K et al (2009) Altered fibrin clot structure/ function in patients with idiopathic venous thromboembolism and their relatives. Blood 114:4272-4278

24. Lisman T, Leebeek FWG, Mosnier LO, Bouma BN, Meijers JC, Janssen HL et al (2001) Thrombin-activatable fibrinolysis inhibitor deficiency in cirrhosis is not associated with increased plasma fibrinolysis. Gastroenterology 121:131-139

25. Undas A, Zalewski J, Krochin M, Siudak Z, Sadowski M, Pręgowski J et al (2010) Altered plasma fibrin clot properties are associated with in-stent thrombosis. Arterioscler Thromb Vasc Biol 30:276-282

26. Blombäck B, Carlsson K, Hessel B, Liljeborg A, Procyk R, Aslund N (1989) Native fibrin gel networks observed by 3D microscopy, permeation and turbidity. Biochim Biophys Acta 997:96 - 110

27. Pankiw-Bembenek O, Zalewski J, Goralczyk T, Undas A (2012) A history of early stent thrombosis is associated with prolonged clot lysis time. Thromb Haemost 107:513-520

28. Lüscher TF, Steffel J, Eberli FR, Joner M, Nakazawa G, Tanner FC et al (2007) Drug-eluting stent and coronary thrombosis: biological mechanisms and clinical implications. Circulation 115:1051-1058

29. Sadowski M, Ząbczyk M, Undas A (2014) Coronary thrombus composition: links with inflammation, platelet and endothelial markers. Atherosclerosis 237:555-561

30. Spiel AO, Gilbert JC, Jilma B (2008) Von Willebrand factor in cardiovascular disease: focus on acute coronary syndromes. Circulation 117:1449-1459

31. Tsakiris DA, Tschöpl M, Jäger K, Haefeli W, Wolf F, Marbet G (1999) Circulating cell adhesion molecules and endothelial markers before and after transluminal angioplasty in peripheral arterial occlusive disease. Atherosclerosis 142:193-200

32. Kotschy D, Kotschy M, Socha P, Masłowski L, Kwapisz J, Żuk N at al (2015) Selected endothelial hemostatic markers in patients with peripheral arterial disease after endovascular revascularization and restenosis formation. Postepy Hig Med Dosw 69:905-912

33. Wolberg AS, Campbell RA (2008) Thrombin generation, fibrin clot formation and hemostasis. Transfus Apher Sci 38:15-23

34. ten Cate H, Hemker HC (2016) Thrombin generation and atherothrombosis: what does the evidence indicate? J Am Heart Assoc 8:e003553. https://doi.org/10.1161/JAHA.116003553

35. Williams S, Fatah K, Hjemdahl P, Blombäck M (1998) Better increase in fibrin gel porosity by low dose than intermediate dose acetylsalicylic acid. Eur Heart J 19:1666 - 1672

36. Undas A, Celinska-Löwenhoff M, Löwenhoff T, Szczeklik A (2006) Statins, fenofibrate, and quinapril increase clot permeability and enhance fibrinolysis in patients with coronary artery disease. Thromb Haemost 4:1029-1036

37. Zabczyk M, Plens K, Wojtowicz W, Undas A (2017) Prothrombotic fibrin clot phenotype is associated with recurrent pulmonary embolism after discontinuation of anticoagulant therapy. Arterioscler Thromb Vasc Biol 37:365-373. DOI:101161/ATVBAHA. 116.308253

38. Cieslik J, Mrozinska S, Broniatowska E, Undas A (2018) Altered plasma clot properties increase the risk of recurrent deep vein thrombosis: a cohort study. Blood 131:797-807. https://doi. org/10.1182/blood-2017-07-798306

Publisher's Note Springer Nature remains neutral with regard to jurisdictional claims in published maps and institutional affiliations. 